\title{
An Analysis of the Integration and Reconstruction of Micro-class, MOOC and Flipped Classroom
}

\author{
Zeli Xie \\ School of Foreign Languages, Shanxi Normal University, Linfen, China
}

\begin{abstract}
This paper analyzes the advantages and disadvantages of micro-class, MOOC and flipped classroom, and comprehensively analyzes them from the theoretical level. The research results show that the integration and reconstruction of them will help students to learn foreign languages better and achieve the expected results in the foreign language teaching. This will provide a new perspective and reference for the further study of foreign language teaching in China.
\end{abstract}

Index Terms - micro-class, MOOC, flipped classroom, integration and reconstruction

\section{INTRODUCTION}

With the progress of society, the development of technology, and the prosperity of our nation, people gradually realize that technology plays a very significant role in those aspects which requires them to pay more attention to it and apply it to their daily life. What's more, if people connect technology to current education, they will have access to acquire much knowledge in different ways. That is to say, people can accept traditional education and online education, such as online courses to help them learn a lot at any time. Nowadays, people are in a big date era which makes more and more online courses emerge and quite a few people choose online education.

As we all know, the purpose of education is to learn rather than teach. Unfortunately, traditional education emphasizes "teaching" and neglects "learning", and foreign language education is no exception. The teaching and learning model of foreign language education in the big data era changes, the perception of teachers and students, the role of teachers and learners, learning materials, learning environment and assessment and testing have changed (Liu Runqing, 2014, p. 2). This paper aims to explore feasible paths of the current foreign language teaching reform of China by analyzing the relationship between micro-class, MOOC, and flipped classroom, and tries to integrate and reconstruct them to analyze the foreign language teaching paradigm from micro-class to MOOC and flipped classroom.

\section{LITERATURE REVIEW}

It's necessary to know more about the researches that people do on micro-class, MOOC and flipped classroom.

\section{A. The Research Status of Micro-class and MOOC}

The integration of foreign language educational information technology and foreign language courses will inevitably lead to a "silent teaching revolution" (Hu Jiasheng \& Jin Yan, 2015, p. 115). Micro-class, MOOC and flipped classroom are the incarnations of modern educational technology, and these three classes are closely related. Micro-class includes micro-courses and micro-lectures (Zhao Guodong, 2014, p. 232).

MOOC was first put forward by Canadian scholars Dave Cormier and Bryan Alexander in 2008. Liu Runqing (2014, p. 3) stated that MOOC refers to massive open online courses, and it is also translated into the on-screen course. Wang Zhuli (2015, p. 18) stated that it concludes behavioral MOOC which focuses on imparting knowledge and connective MOOC which emphasizes the connection and social network construction. Flipped classroom as a new teaching method or teaching mode is a kind of subversion to traditional teaching, and it is also a "micro innovation" which is based on criticism and inheritance (Rong Mei \& Peng Xuehong, 2015, p. 109). Kang Yanru (2018) proposed that there are plenty of interesting and comprehensible learning resources with high quality on MOOC. MOOC supplies personalized teaching videos, which could meet different participants' demands (Yang Xiaoli \& Han Lei, 2019, p. 23). Although micro-class, MOOC and flipped classroom have their own characteristics, they are related and they all show the learning fragmented characteristics of the digital era (Wang Zhuli, 2015, p. 18). However, people now view them in an attitude of binary and opposition, and few studies have adopted an attitude of integration and reconstruction to explore the relationship between them. This paper takes the relationship between these three modes as an entry point to do more in foreign language teaching reform.

\section{B. The Research Status of Flipped Classroom}

In recent years, some scholars began to think rationally about flipped classroom, and carried out teaching practice 
and reflective research of flipped classroom (Zhu Zhiting et al., 2015, p. 69). Zhang Jinlei \& Wang Ying (2012, p. 12) pointed that a flipped classroom is a classroom that swaps the arrangement of knowledge imparting and knowledge internalization comparing to traditional classroom. In the flipped classroom, the roles of teachers and students have been changed and the class time should have a new plan. Information technology and activity learning construct an individuation and cooperative learning environment for learners to create new learning culture. "Bergmann and Sams's flipped classroom model has created a classroom structure that allows students to take responsibility for their learning both inside and outside the classroom" (Eric \& Martin, 2011, pp. 10-13). Some scholars also discussed the construction of foreign language teaching mode based on flipped classroom, and the integration of MOOC and flipped classroom (Zeng Mingxing et al., 2015, p. 103; Hu Jiehui \& Wu Zhongjie, 2014, pp. 40-42; Hu Liru \& Zhang Baohui, 2016 , pp. 52-53). In addition, there are scholars who combine professional foreign language teaching, for example, Wang Honglin (2015, p. 59) who carries out research on teaching actions of flipped classroom for interpretation teaching. He Kekang (2014, p. 6) attempted to predict its future development in China by analyzing the nature of the flipped classroom. From the surveys of Chinese and American researchers, primary and secondary school principals, teaching and research staff, university professors and other front-line teachers and parents of students, it is not difficult to find that their attitude towards flipped classroom is quite controversial. There are three attitudes towards it, such as absolute support, resolute opposition and upholding neutral (Rong Mei \& Peng Xue, 2015, p. 110).

\section{Advantages and Disadvantages of Flipped Classroom}

The teaching process of flipped classroom contains three stages. Teachers make micro-class, and students learn independently before class. Teachers answer questions, and these questions will be discussed by teachers and students, and students display their achievements to finish knowledge internalization and application in class. Students expand and deepen knowledge to change knowledge into ability after class. The teaching process of traditional class also contains three stages. Students prepare new lessons before class. Teachers teach in class. Students do homework after class. From the two teaching procedures, people can find flipped classroom teaching reverses the traditional teaching procedures, and the knowledge is taught before class, and the traditional after-school assignments are placed in the classroom. However, the changes brought about by flipped classroom are far from being reversed by the teaching process.

As we can see, both the flipped classroom and the traditional teaching emphasize pre-class, while-class and post-class teaching, but the focus is different. First of all, the purpose of them is different. Traditional teaching advocates that students who prepare for class are for the purpose of better understanding the content taught by the teacher. Teachers are mainly teaching knowledge, and they add some processes of asking questions and let students answer to test whether the students understand what they have learned in class. Students do homework to practice and consolidate to test their understanding and memory, and this kind of homework pays less attention to application and innovation after class.

The flipped classroom allows teachers to arrange personalized tasks like listening to English broadcast, reading English novels or writing English compositions and provide individualized discussions and assessment, which could inspire their interest and enthusiasm in learning. The flipped classroom advocates students to study independently before class. And teachers answer questions to help students to master knowledge and achieve knowledge internalization in the class. After class, students expand and deepen knowledge to change knowledge into ability. Second, the focus of the two types of learning is different. Traditional classroom teaching focuses on the understanding and memory of knowledge, and pays insufficient attention to the application and innovation of knowledge. The flipped classroom helps students internalize and apply knowledge to reach a higher level. Besides, there are differences in the attitude towards teaching and learning. The traditional classroom pays attention to what teachers teach and how to teach. Teachers are mainly responsible for the success or failure of teaching. The flipped classroom emphasizes the subjective status of students, pays attention to what they learn, how to learn, and students are responsible for their own learning. Besides, the diverse interactive activities in the flipped class can expedite the chances for teacher-to-student and student-to-student communication, which is salutary to develop better relationships between teachers and students. Therefore, it has been suggested that the flipped classroom is a subversion of traditional teaching. The author believes that it is better to view it as reconstruction of the teaching and learning concepts in essence, because the flipped classroom reaches the target that teacher draws attention to student's learning rather than teacher's teaching.

1. Advantages of flipped classroom

Goodwin \& Miller (2013, pp. 15-17) stated that the flipped classroom flips not only the class or the classroom, but also the teaching paradigm. If teachers are changed from a knowledge importer to a coach, they will carefully observe and discover the real needs of the students which will help students achieve deep learning. They also pointed out that the characteristics of the flipped classroom contain: (1) increasing the interaction between teachers and students; (2) facilitating teachers to provide immediate feedback; (3) students can learn intently; (4) students can control their learning progress according to their own needs; (5) the supervision of teachers can make the homework more meaningful in class. Besides, Cockrum (2014, p. 4) stated, "Flipped benefits students of all abilities".

As to the effect of the flipped class, He Kekang $(2014$, p.8) puts forward the following views: (1) It can reflect the advantages of mixed learning; (2) It fits with human cognitive rules; (3) It helps to build a new type of teacher-student relationship; (4) It can make teaching resources be effectively used and researched and developed; (5) It fully reflects 
the new concept of "generating curriculum". Zhu Zhiting et al. $(2015,13)$ proposed that the flipped classroom is conducive to deep learning, which can help students become active, prompt learning reflection, participate in activities to achieve knowledge internalization. Summarizing the above points, we can summarize the main advantages of the flipped class. For example: (1) Students review what they have learned in class before class, which helps to effectively use time in class. Students who use pre-class time for knowledge memory and understanding can implicitly lengthens their learning time and help to improve the teaching effect; (2) Students who have discussions, ask and answer questions, show their learning achievement will help them deepen the understanding, internalization and application of knowledge points; (3) Personalized learning pays attention to the individual differences of students, and advocates teaching students in accordance with their aptitude, which helps to motivate students. Students can control the learning steps autonomously, choose their own learning content according to the actual situation, and can learn step by step. In addition, the flipped classroom makes students become more responsible for their own learning and it provides more opportunities for knowledge output in the form of personal presentation, dialogues in pairs, performance in groups and so on. Learners who attend the flipped class conduct various active and collaborative tasks and assignment instead of passively taking notes and memorizing language points.

2. Disadvantages of the flipped classroom

According to relative research, the flipped classroom has some disadvantages. For example: (1) Although teachers make teaching videos before class, there is no teaching differences with traditional teaching in that it is also a mode of teacher-centered and it is mainly teaching which cannot pay attention to individual differences and different learning style of students; (2) Some people are worried about whether the functions of teachers can be weakened or not, and whether students can learn as required without interaction with teachers because of the flipped class teaching stressing the mode of student-centered; (3) Because most teachers are not technicians, the quality of video production is difficult to guarantee, and low-quality video is not conducive to the transfer of knowledge, and teachers cannot monitor students' understanding of what they have learned, and teachers cannot provide timely assistance when students need help, especially when they need instant knowledge and information (Milan, 2012). However, Goodwin \& Miller (2013) provided opposite views that they think teachers have chance to provide students with instant feedback with the increase of interaction between students and teachers in the flipped classroom. People think that teachers who provide one-to-one tutoring and feedback are much more than provided in traditional class.

Sams \& Bergmann (2013, p. 9) put forward the concept of flipping learning. If the flip is appropriate, it can improve the learning effect of students from the current practice of flipping teaching. However, in order to achieve success in the flipped classroom, teachers must change their mindsets and improve their abilities and practice boldly (Li Yun, 2014, 3). People find that using the ubiquitous learning sharing platform to construct a college English flipped class teaching model can help improve English teaching effectiveness and learning efficiency. The author believes that the concept of flipping learning focuses on the construction of knowledge and the cultivation of abilities, emphasizing learning efficiency and meeting the needs of personalized learning in the context of big data in the information age.

\section{INTEGRATION AND RECONSTRUCTION}

Learning in the era of big data presents the fragmentation characteristics of learning content, learning time and learning style, which needs to use an integrated approach to have a creative reconstruction of fragmented knowledge (Wang Zhuli, 2015, 17 ). In fact, the current research on micro-class, MOOC and flipped classroom is also fragmented. However, few people try to integrate and reconstruct them. This study analyzes the micro-class, MOOC and flipped classroom from the perspective of multi-theoretical theory, focusing on the relationship between them to have a creative integration and reconstruction of the current fragmentation research to promote foreign language teaching reform and improve foreign language teaching effect.

\section{A. The Cause of Integration and Reconstruction}

In the past, the study of micro-class, MOOC and flipped classroom mostly adopted the method of "dual opposition", paying more attention to the opposite between things, and paying less attention to the intersection and integration of them. When discussing micro-class, MOOC and flipped classroom, there are examples on the research of putting related concepts in opposite aspects. For example: (1) in the discussion of flipped classroom, many studies have not fully explored the concept of "flip", and they just put the teacher center and the student center, passive acceptance and active exploration in opposite aspects. As everyone knows, even if the teacher teaches all the time, there will be a difference between students' active absorption and passive acceptance. Moreover, some students may concentrate on the teaching for a while, and they may be absent-minded for the rest time during the whole teaching process. (2) When discussing micro-class and MOOC, people always put "teaching" and "learning" in opposite aspects. "Teaching" and "learning" were originally two sides of things, and the purpose of "teaching" is to promote "learning", which is also the purpose of MOOC. (3) As to put "traditional teaching" and "flipped classroom" in opposite aspects, most people have a negative attitude towards "tradition", especially the traditional teaching based on teacher teaching. In fact, some face to face teaching may help students to understand and absorb knowledge well, such as knowledge courses. There are also differences between lectures and lectures. Some courses may make students sleepy, while some lectures may make students enjoyable. Therefore, people should analyze the advantages and disadvantages of traditional teaching and 
flipped classroom in objective and comprehensive perspective. (4) When studying MOOC, people pay too much attention to online teaching, and ignore communication and interaction of offline. They put online and offline learning and face-to-face teaching and communication in opposite aspects. In fact, the effective connection and integration of them can help students a lot. (5) When implementing the flipped classroom, people put the classroom and the extracurricular learning on opposite aspects. In fact, people should connect classroom learning and extracurricular learning to study well.

\section{B. Approaches of Integration and Reconstruction}

1. Integration and reconstruction of educational technology

People argue that the purpose of using educational technology is to enhance the interaction between teachers and students, but does not replace the functions of teachers. Zhu Zhiting \& Sun Yanyan (2015, P. 69) proposed that "no matter how technology changes, the core of education is students. In the context of the digital age, how to improve the learning experience of students is an important issue." Therefore, the design of the micro-class, the use of MOOC and the implementation of flipped classroom, teachers should pay attention to the learning experience of students, increase the design of interactive questions, and integrate online and offline communication and interaction between teachers and students. People believe that the MOOC and the flipped classroom are the two teaching modes that are concerned by the education community, and each with its own advantages and disadvantages. Considering this, they put forward to construct a deep learning field that integrates MOOC and flipped classroom, which is to integrate the MOOC's resources into the whole process of flipped classroom teaching to provide an efficient online learning platform, learning tools and quality learning resources for flipped classroom. In fact, this initiative is an attempt to integrate and reconstruct educational technology and foreign language teaching. If we aim to achieve depth and effective learning, we should fully utilize the educational technology to promote teaching reform.

2. Integration and reconstruction of teaching and learning

The author believes that classroom teaching in the school education environment is different from the self-learning out of school education. And efficient classroom teaching should be based on effective learning, and consider the role of teachers and students. On the one hand, teachers should aim at promoting students' effective learning in designing teaching activities, and aim at promoting students' actions to achieve effective learning through the joint action of teachers and students. On the other hand, students should be responsible for their own learning and know how to learn. In this process, teachers, as the leader of teaching, should also achieve sustainable professional development through lifelong learning, thus ensuring that teaching reforms are truly deepened.

\section{Suggestions for Dynamic Integration and Reconstruction}

\section{Dynamic flip}

According to Bloom's educational goals and the learner's knowledge level, the teaching objectives are divided into six stages from low to high such as memory, understanding, application, analysis, evaluation and creation. Sams \& Bergmann (2013, P. 7) thought that not all classes are suitable for flipping. For example, Socratic or inquiry-based courses or courses without a lot of factual content are not suitable for flipping. In fact, whether or not to implement flipping, how much extent to flip, how to flip, etc., which needs to take into account the course content, teaching objectives, students' actual level and cognitive characteristics, etc.

2. Dynamic integration and reconstruction

Sams \& Bergmann (2013, P. 10) proposed a teaching video for the use of flipped classroom. The value is that students should do some preparation like understanding and reciting knowledge before class, and they need to do some hard work like application, analysis, evaluation and creation in class. In addition, they realized that not all students are suitable for video learning, just as not all students like textbooks, lectures and so on. Therefore, It is necessary to provide students with varieties of choices rather than requiring students to complete the same activities. Based on these issues, teachers should provide students with multi-integration approaches according to students' practical situations and cognitive levels by using dynamic integration and reconstruction during flipped classroom. In addition, it is necessary to carry out philosophical thinking on micro-class, MOOC and flipped classroom, break the research paradigm of "dual opposition", adopt multi-integration paradigm, and carry out dynamic analysis from different perspectives.

3. Evaluations on effects of integration and reconstruction

In order to objectively evaluate the integration effect of micro-class, MOOC and flipped classroom, we need to analyze them through various ways. Teaching should focus on students' learning interest, ability changes in autonomous and cooperative learning, and changes in students' critical thinking abilities, and should not only focus on students' grades and evaluation results. Instead, we should adopt multi-disciplinary measures to assess the effectiveness of teaching and learning like testing and evaluation, questionnaires, classroom observations, students' learning reflection logs, teachers' reflection logs, and academic level tests.

\section{CONCLUSION}

This study attempts to pay more attention to the relationship between micro-class, MOOC and flipped classroom 
from the perspective of integration. Considering the current situation of foreign language teaching in China in the environment of current big data, we have a research on the integration and reconstruction of them to provide a new perspective for future foreign language teaching research. For new things like micro-class, MOOC and flipped classroom, we should not treat them in a total acceptance or a total negative attitude. Not only do we need to think comprehensively, seek truth from facts, dig deeper education and teaching concepts, and seek the essence through phenomena, but also we need to carry out more teaching action research and empirical research in combination with teaching practice to test its effectiveness. Only in this way can we objectively exam the adaptability of them in the context of China's education.

\section{REFERENCES}

[1] Cockrum, T. (2014). Flipping Your English Class to Reach All Learners. New York: Routledge.

[2] Eric, B. \& H. Martin. (2011). Flipping Your Classroom. Science Teacher, 2, 10-13.

[3] Goodwin, B. \& K. Miller. (2013). Evidence on flipped classrooms is still coming in. Educational Leadership, 3, 15-17.

[4] He Kekang. (2014). Look forward to the Future Development of Flipped Classroom in China from the Essence of Flipped Classroom. E-Education Research, 7, 5-8.

[5] Hu Jiasheng, Jin Yan. (2015). Courses Construction under e-Educology of Foreign Languages in View of TPACK. China Educational Technology, 4, 114-116.

[6] Hu Jiehui \& Wu Zhongjie. (2014). An Empirical Study on the MOOC-based College English Flipped Classroom Instructional Model. CAFLE, 6, 40-42.

[7] Hu Liru \& Zhang Baohui. (2016). Flipped Classroom and Flipped Learning: Analyze the Efficacy of "Flipping". Journal of Distance Education, 4, 52-53.

[8] Li Yun. (2014). The Rational Thinking of Popularity of "Flipped Classroom" in China. Curriculum, Teaching Material and Method, 10, 18-20.

[9] Liu Runqing. (2014). Foreign Language Education and Research in the Era of Big Data. Contemporary Foreign Languages Studies, 7, 2-3.

[10] Milman, N. (2012). The Flipped Classroom Strategy: What Is It and How Can It Be Used?. Distance Learning, 3, 11-15.

[11] Rong Mei \& Peng Xuehong. (2015). A Study on the History, Current Situation and Application of "Flipped Classroom". China Educational Technology, 7, 108-110.

[12] Sams, A. \& J. Bergmann. (2013). Flip your students' learning. Educational Leadership, 6, 8-10

[13] Wang Honglin. (2015). Research on Interpreting Teaching Action Based on Flipped Classroom. Chinese Translators Journal, 1, 59-62.

[14] Wang Zhuli. (2015). Fragment and Reconstruction: Education of Remodeling Internet Thinking. Beijing: Publishing House of Electronic Industry.

[15] Zeng Mingxing et al. (2015). Research of Flipped Classroom Teaching Model Based on MOOC. China Educational Technology, 4, 102-108.

[16] Zhao Guodong. (2014). Design of micro-lecture \& MOOCs. Beijing: Peking University Press.

[17] Zhu Zhiting \& Guan Yuqi \& Qiu Huixian. (2015). Domestic Application Practice and Reflection of Flipped Classroom. E-Education Research, 6, 68-70.

[18] Zhu Zhiting \& Sun Yanyan. (2015). Seamless Learning as a New Normal Learning Form in Digital Age. Open Education Research, 1, 13-14.

Zeli Xie was born in Shanxi Province, China in 1993. She is studying for her Master's Degree in foreign linguistics and applied linguistics in Shanxi Normal University, China in 2020. Her research interests include linguistics, English teaching and discourse analysis. 